OPEN ACCESS

Edited by:

Fangang Meng,

Capital Medical University, China

Reviewed by:

Dianyou Li,

Shanghai Jiao Tong University, China Yutong Bai,

Capital Medical University, China

${ }^{*}$ Correspondence:

Fabin Lin

fabinlin@hotmail.com

Guoen Cai

cgessmu@fjmu.edu.cn

Specialty section: This article was submitted to

Motor Neuroscience,

a section of the journal

Frontiers in Human Neuroscience

Received: 29 July 2021 Accepted: 02 September 2021

Published: 22 October 2021

Citation:

Chen T, Lin F and Cai G (2021) Comparison of the Efficacy of Deep Brain Stimulation in Different Targets in Improving Gait in Parkinson's Disease:

A Systematic Review and Bayesian Network Meta-Analysis. Front. Hum. Neurosci. 15:749722. doi: 10.3389/fnhum.2021.749722

\section{Comparison of the Efficacy of Deep Brain Stimulation in Different Targets in Improving Gait in Parkinson's Disease: A Systematic Review and Bayesian Network Meta-Analysis}

\author{
Tianyi Chen ${ }^{1}$, Fabin $\operatorname{Lin}^{2,3 *}$ and Guoen Cai ${ }^{2,3 *}$ \\ 'School of Mathematics, Shandong University, Jinan, China, ${ }^{2}$ Department of Neurology, Fujian Medical University Union \\ Hospital, Fuzhou, China, ${ }^{3}$ Fujian Key Laboratory of Molecular Neurology, Institute of Clinical Neurology, Institute of \\ Neuroscience, Fujian Medical University, Fuzhou, China
}

Background: Although a variety of targets for deep brain stimulation (DBS) have been found to be effective in Parkinson's disease (PD), it remains unclear which target for DBS leads to the best improvement in gait disorders in patients with PD. The purpose of this network meta-analysis (NMA) is to compare the efficacy of subthalamic nucleus (STN)-DBS, internal globus pallidus (GPi)-DBS, and pedunculopontine nucleus (PPN)-DBS, in improving gait disorders in patients with PD.

Methods: We searched the PubMed database for articles published from January 1990 to December 2020. We used various languages to search for relevant documents to reduce language bias. A Bayesian NMA and systematic review of randomized and non-randomized controlled trials were conducted to explore the effects of different targets for DBS on gait damage.

Result: In the 34 included studies, 538 patients with PD met the inclusion criteria. The NMA results of the effect of the DBS "on and off" on the mean change of the gait of the patients in medication-off show that GPi-DBS, STN-DBS, and PPN-DBS are significantly better than the baseline [GPi-DBS: $-0.79(-1.2,-0.41)$, STN-DBS: $-0.97(-1.1,-0.81)$, and PPN-DBS: $-0.56(-1.1,-0.021)]$. According to the surface under the cumulative ranking (SUCRA) score, the STN-DBS (SUCRA $=74.15 \%$ ) ranked first, followed by the GPi-DBS $(S U C R A=48.30 \%)$, and the PPN-DBS $(S U C R A=27.20 \%)$ ranked last. The NMA results of the effect of the DBS "on and off" on the mean change of the gait of the patients in medication-on show that, compared with baseline, GPi-DBS and STN-DBS proved to be significantly effective [GPi-DBS: $-0.53(-1.0,-0.088)$ and STN-DBS: $-0.47(-0.66,-0.29)$ ]. The GPi-DBS ranked first (SUCRA $=59.00 \%$ ), followed by STN-DBS(SUCRA $=51.70 \%$ ), and PPN-DBS(SUCRA $=35.93 \%$ ) ranked last.

Conclusion: The meta-analysis results show that both the STN-DBS and GPi-DBS can affect certain aspects of PD gait disorder.

Keywords: Parkinson's disease, deep brain stimulation, Bayesian network meta-analysis, gait, motor symptoms 


\section{INTRODUCTION}

Parkinson's disease (PD) is currently the second most prevalent neurodegenerative disease worldwide. Gait disorders widely and severely affect patients with PD as they significantly limit the ability of the patient to walk and often cause falls and fall-related injuries. In addition, with the progression of the disease, their frequency and severity gradually increase (Nonnekes et al., 2015, 2019). Dopamine therapy and surgery are commonly used to treat gait disorders in patients with early and mid-stage PD, but their beneficial effect is minimal for patients with advanced PD (Gazewood et al., 2013). Deep brain stimulation (DBS) is a novel treatment for advanced PD-related gait disorders (Ferraye et al., 2008). Compared with the traditional treatments for PD, DBS has the advantages of reversibility, preservation of neuronal tissue, and adjustability of the treatment plan according to the disease state of the patient. It is believed that the subthalamic nucleus (STN) (Remple et al., 2011; Jahanshahi et al., 2015), internal globus pallidus (GPi) (Okun, 2012), and pedunculopontine nucleus (PPN) are the stimulation targets for improving gait disorders in patients with advanced PD.

Some randomized controlled trials were unable to implement two specific interventions, resulting in the inability to obtain direct evidence from face-to-face trials. As a result, it can be challenging to evaluate the effectiveness of many clinically indicated interventions available and determine the best intervention (Nikolakopoulou et al., 2018). Through network-meta-analysis (NMA), inferences can be made about every possible comparison between a pair of interventions in the network, even if some comparisons have never been evaluated in actual trials (Bafeta et al., 2013; Dias and Caldwell, 2019). Ultimately, we can combine the direct and indirect comparisons and determine the best intervention.

The treatment of gait disorders is a challenge. Realizing that few studies directly compare the efficacy of DBS with different stimulation targets, we conducted an NMA to evaluate the potential effects of STN-DBS, GPi-DBS, and PPN-DBS in the treatment of PD gait.

The Unified Parkinson's Disease Rating Scale (UPDRS) is currently the most widely used clinical grading system for PD (Movement Disorder Society Task Force on Rating Scales for Parkinson's Disease, 2003). This study evaluates the 3.29-step item of gait in the UPDRS. Therefore, our goal is to compare and rank the therapeutic effects of these three types of interventions on PD gait.

\section{METHOD}

This NMA is implemented in accordance with the Preferred Reporting Items for Systematic Reviews and Meta-Analyses extension statement for NMA.

\subsection{Search Method}

We searched the PubMed database for articles published from January 1990 to December 2020 and searched for relevant documents in various languages to reduce language bias. However, ultimately, only documents in English were considered appropriate. After that, we also screened the references of the retrieved articles to determine related research studies.

\subsection{Eligibility Criteria}

1. Clinical trials of using DBS to treat idiopathic PD.

2. Research object: patients clinically diagnosed with PD.

3. Results: studies used the UPDRS III and UPDRS III item 29 to evaluate therapeutic efficacy.

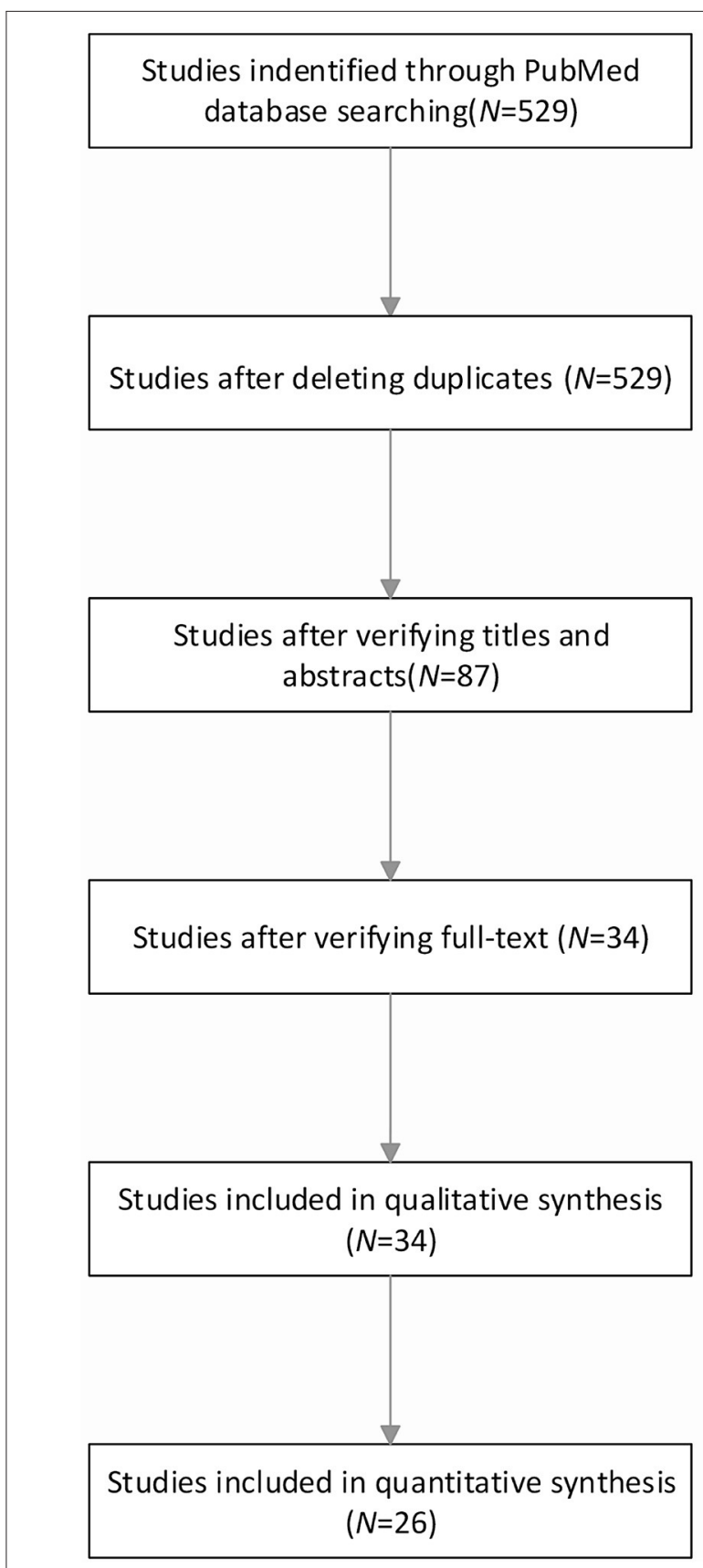

FIGURE 1 | Flowchart of study selection. 


\section{Amed-off/stim-off vs. med-off/stim-on B med-on/stim-off vs. med-on/stim-on \\ C med-off/stim-off vs. med-on/stim-off \\ D med-off/stim-on vs. med-on/stim-on
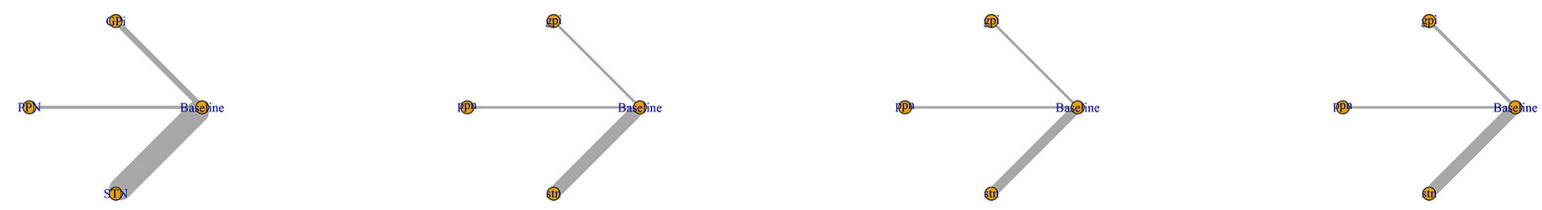

Emed-off/stim-off vs. med-off/stim-on

F med-on/stim-off vs. med-on/stim-on

G med-off/stim-off vs. med-on/stim-off

H med-off/stim-on vs. med-on/stim-on
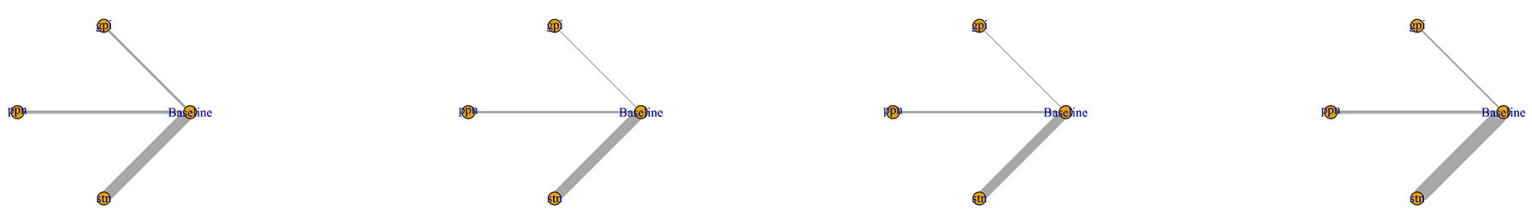

FIGURE 2 | Network plot for all studies. (A) UPDRS III-Gait med-off/stim-off vs. med-off/stim-on. (B) UPDRS III-Gait med-on/stim-off vs. med-on/stim-on. (C) UPDRS III-Gait med-off/stim-off vs. med-on/stim-off. (D) UPDRS III-Gait med-off/stim-on vs. med-on/stim-on. (E) UPDRS III- Total med-off/stim-off vs. med-off/stim-on. (F) UPDRS III- Total med-on/stim-off vs. med-on/stim-on. (G) UPDRS III- Total med-off/stim-off vs. med-on/stim-off. (H) UPDRS III- Total med-off/stim-on vs.

med-on/stim-on.

4. Including one or more of the following three surgical methods: STN-DBS, GPi-DBS, and PPN-DBS.

\subsection{Exclusion Criteria}

1. Clinical trials of DBS in the treatment of diseases other than PD.

2. No clinically controlled trials were conducted at the same time.

3. Lost data or data that cannot be extracted.

4. Studies used the MDS-UPDRS III and MDS-UPDRS III item 29 to evaluate therapeutic efficacy.

\subsection{Quality Assessment and Data Extraction}

The Cochrane Collaboration's risk-of-bias tool was used to assess the quality of previous systematic reviews. The quality of each manuscript was evaluated by two researchers and then discussed with the main researcher to reach an agreement. We extracted the following variables from the collected manuscripts: name of the first author, date of publication, number of participants, age of participants, intervention measures, sex ratio, disease duration, post-surgery duration, and funding.

\subsection{Effective Measurement}

The UPDRS is currently the most commonly used clinical grading scale system for PD. The UPDRS III score is the main evaluation index for PD therapeutic research, and the UPDRS III gait sub-score is defined as the UPDRS III item 29 score. Therefore, we used the UPDRS III item 29 to evaluate the improvement of gait in patients with PD. In addition, the UPDRS III total score was used to assess the improvement of motor symptoms in patients with PD.

\subsection{Statistical Analysis}

In this study, the $\mathrm{R}$ language ( $\mathrm{R}$ program software V.3.5.3, CRAN Project) was used to conduct NMA in order to compare the efficacy of different therapies. The specific method refers to our previous study (Lin et al., 2021). In short, NMA was performed based on the Bayesian framework, using the Markov Chain Monte Carlo method in the $\mathrm{R}$ software, including 4 chains with over-dispersed initial values and Gibbs sampling based on 50,000 iterations after 20,000 aging stages. The mean difference and $95 \%$ CI of the difference were obtained, and the significance level was 0.05 . Additionally, the rank probability of each clinical outcome was assessed. The deviation information criterion (DIC) was used to evaluate the goodness of fit in this study. The quality of the model is negatively correlated with the value of DIC. By comparing the DIC values between the models, the suitability of the models can be assessed (Carpinella et al., 2007). To be able to determine whether small research effects exist, we examined each result and compared the adjusted funnel chart. In this study, we drew a funnel chart of the mean difference between all comparisons after treatment and baseline.

\section{RESULTS}

\subsection{Research Description}

The basic process of research data collection is illustrated in Figure 1. The network plot of the overall efficacy is shown in Figure 2. The basic information of the data of the study is shown in Table 1. The comparison-adjusted funnel plot for the network of the functional outcome is shown in Figure 3 and the risk of bias for the included trials is shown in Figure 4. In our first search, we identified 529 articles and subsequently eliminated 442 irrelevant articles based on the title and abstract of the article. Then, we carefully reviewed the full text of the remaining 87 articles and eliminated 53 of them. Our exclusion criteria were as follows: no extracted data; no available data; inappropriate diagnosis, and comment/overview. Ultimately, this study included a total of 34 studies and 26 of which were included in quantitative studies (Gálvez-Jiménez et al., 1998; Kumar et al., 1999; Obeso et al., 2001; Ogura et al., 2004; Erola et al., 2005; 
TABLE 1 | Characteristics of included studies.

\begin{tabular}{|c|c|c|c|c|c|c|c|c|}
\hline Number & Intervention & Author\&Year & $\begin{array}{l}\text { Sample } \\
\text { size }\end{array}$ & $\begin{array}{c}\text { Age } \\
\text { (mean (SD) y) }\end{array}$ & $\begin{array}{l}\text { Gender } \\
\text { (M/F) }\end{array}$ & $\begin{array}{l}\text { Disease } \\
\text { duration } \\
\text { (y ears) }\end{array}$ & $\begin{array}{l}\text { Post } \\
\text { surgery } \\
\text { duration }\end{array}$ & Funding \\
\hline 1 & STN-DBS & Tir, 2007 & 100 & $58.7 \pm 8.2$ & $55 / 45$ & $13.6 \pm 4.4$ & $12 \mathrm{~m}$ & / \\
\hline 2 & $\begin{array}{l}\text { single electrode guided } \\
\text { STN-DBS or multiple } \\
\text { electrode guided STN-DBS }\end{array}$ & Temel, 2007 & 55 (S:32 M:23) & $\begin{array}{c}61.6(\mathrm{~S}: 59.4 \pm 7 \\
\mathrm{M}: 64.6 \pm 9.6)\end{array}$ & $\begin{array}{c}\text { 36/19 (S:21/11 } \\
M: 15 / 8)\end{array}$ & $\begin{array}{l}12.3(\mathrm{~S}: 13.1 \pm 5.1 \\
\mathrm{M}: 11.3 \pm 5.6)\end{array}$ & $12 \mathrm{~m}$ & I \\
\hline 3 & STN-DBS & Tabbal, 2007 & 72 & $63 \pm 8.2$ & $41 / 31$ & $14.5 \pm 6.5$ & $6 \mathrm{~m}$ & $\begin{array}{l}\text { The Sam and Barbara Murphy Fund, the } \\
\text { Elliot H. Stein } \\
\text { Family Fund }\end{array}$ \\
\hline 4 & STN-DBS & Simuni, 2002 & 12 & $58 \pm 11$ & $10 / 2$ & $12 \pm 4$ & $12 \mathrm{~m}$ & / \\
\hline 5 & STN-DBS & $\begin{array}{l}\text { Rodrlguez-oroz, } \\
2005\end{array}$ & 69 (S:49 M:20) & $\begin{array}{c}58.6(\mathrm{~S}: 59.8 \pm 9.8 \\
\text { G:55.8 } \pm 9.4)\end{array}$ & $\begin{array}{c}38 / 31 \text { (S:25/24 } \\
\text { G:13/7) }\end{array}$ & $\begin{array}{c}14.2(\mathrm{~S}: 14.1 \pm 5.9 \\
\text { G:14.4 } \pm 5.7)\end{array}$ & $3-4 y$ & Medtronic Europe \\
\hline 6 & STN-DBS & Panida, 2007 & 33 & $53.4 \pm 8.3$ & $24 / 9$ & / & $5 y$ & I \\
\hline 7 & GPi-DBS & Ogura, 2004 & 30 & 57.7 & $16 / 14$ & 8.4 & $12 \mathrm{~m}$ & / \\
\hline 8 & $\begin{array}{l}\text { GPi-DBS (There is an } \\
\text { example of GPi+VIM) }\end{array}$ & Nestor, 1998 & 5 & $63.2 \pm 7.5$ & $4 / 1$ & $10.2 \pm 4.7$ & $3 \mathrm{~m}$ & $\begin{array}{l}\text { Medtronic, Minneapolis, MN, the } \\
\text { National Parkinson Foundation, Miami, FI } \\
\text { and the Parkinson Foundation of Canada }\end{array}$ \\
\hline 9 & STN-DBS & Lefaucheur, 2008 & 54 & 59 & $34 / 20$ & 14 & $12 \mathrm{~m}$ & / \\
\hline 10 & STN-DBS & Erola, 2005 & 29 & $60 \pm 8$ & $20 / 9$ & $13 \pm 7$ & $12 \mathrm{~m}$ & $\begin{array}{l}\text { Finnish Parkinson } \\
\text { Foundation }\end{array}$ \\
\hline 11 & STN-DBS or GPi-DBS & DBSPDG, 2001 & 134 (S:96 G:38) & $\begin{array}{c}58.1(\mathrm{~S}: 59.0 \pm 9.6 \\
\text { G:55.7 } \pm 9.8)\end{array}$ & $\begin{array}{c}\text { 87/37 (S:60/36 } \\
\text { G:27/11) }\end{array}$ & / & $6 \mathrm{~m}$ & / \\
\hline 12 & STN-DBS & Crenna, 2006 & 10 & $60.2 \pm 4.8$ & $5 / 5$ & $16.9 \pm 5.5$ & $10.4 \pm 7 \mathrm{~m}$ & $\begin{array}{l}\text { Italian } \\
\text { Ministry of Health }\end{array}$ \\
\hline 13 & STN-DBS or GPi-DBS & Burchiel, 1999 & 10 (S:6 G:4) & $\begin{array}{r}56613(\mathrm{~S}: 62.8 \pm \\
12 \mathrm{G}: 46.5 \pm 11)\end{array}$ & $7 / 3$ & $\begin{array}{l}12.4(\mathrm{~S}: 13.6 \pm 5 \\
\text { G:10.6 } \pm 2)\end{array}$ & $3 m$ & $\begin{array}{l}\text { United States Public } \\
\text { Health Service }\end{array}$ \\
\hline 14 & PPNa-DBS & Welter, 2015 & 4 & $62 \pm 9.5$ & $1 / 3$ & $15.8 \pm 5.1$ & $6 m$ & $\begin{array}{l}\text { The Institut National de la Recherche } \\
\text { Me'dicale (INSERM), the 'Institut du } \\
\text { Cerveau } \\
\text { et de la Moelle Epinie're' (ICM) } \\
\text { Foundation, the 'Re'gie Autonome } \\
\text { des Transports Parisiens' (RATP), the } \\
\text { 'Fondation pour la Recherche } \\
\text { Medicale' (FRM) and the programme } \\
\text { 'Investissements d'avenir' } \\
\text { (ANR-10-IAIHU-06) }\end{array}$ \\
\hline 15 & STN-DBS & Vallabhajosula, 2015 & 19 & $61.8 \pm 9$ & $16 / 3$ & $13.6 \pm 4.2$ & I & $\begin{array}{l}\text { The National } \\
\text { Parkinson Foundation Center of } \\
\text { Excellence, the UF Foundation, and } \\
\text { UF Center for Movement Disorders and } \\
\text { Neurorestoration }\end{array}$ \\
\hline
\end{tabular}


TABLE 1 | Continued

\begin{tabular}{|c|c|c|c|c|c|c|c|c|}
\hline Number & Intervention & Author\&Year & $\begin{array}{l}\text { Sample } \\
\text { size }\end{array}$ & $\begin{array}{c}\text { Age } \\
\text { (mean (SD) y) }\end{array}$ & $\begin{array}{l}\text { Gender } \\
\text { (M/F) }\end{array}$ & $\begin{array}{l}\text { Disease } \\
\text { duration } \\
\text { (y ears) }\end{array}$ & $\begin{array}{l}\text { Post } \\
\text { surgery } \\
\text { duration }\end{array}$ & Funding \\
\hline 16 & STN-DBS & Stegemoller, 2013 & 17 & $61.5 \pm 9.2$ & $14 / 3$ & $13.6 \pm 3.9$ & $30.5 \pm 19.2 \mathrm{~m}$ & $\begin{array}{l}\text { The National Parkinson } \\
\text { Foundation UF Center for Excellence and y } \\
\mathrm{NIH} \text { grant 5R03HD054594-02 }\end{array}$ \\
\hline 17 & STN-DBS & Sidiropoulos, 2013 & 45 & $59.5 \pm 7.8$ & $35 / 10$ & $17.8 \pm 5.7$ & $4 y$ & / \\
\hline 18 & STN-DBS & Romito, 2009 & 20 & $56.4 \pm 6.9$ & $11 / 9$ & $14.3 \pm 6.2$ & $5 y$ & $\begin{array}{l}\text { The Italian } \\
\text { Ministry of University and Research } \\
\text { (National Interest Project } \\
\text { number } 2001062543 \text { to AA) }\end{array}$ \\
\hline 19 & STN-DBS or GPi-DBS & Price, 2011 & 37 & $58.8 \pm 7$ & $28 / 9$ & 12.4 & $4 \mathrm{~m}$ & $\begin{array}{l}\text { NINDS K23NS060660 (CP), NIH T35 } \\
07489 \\
\text { (CF), UF National Parkinson Foundation } \\
\text { Center of Excellence and UF } \\
\text { Foundation }\end{array}$ \\
\hline 20 & STN-DBS & Phibbs, 2013 & 20 & 62 & $16 / 4$ & 12.5 & 3y & $\begin{array}{l}\mathrm{NIH} \text { grant 1UL } 1 \text { RR024975 NCRR and } \\
\text { grant UL1 TR000445 from NCATS/NIH }\end{array}$ \\
\hline 21 & STN-DBS & Nardo, 2014 & 9 & $66.4 \pm 6.0$ & $7 / 2$ & $3.1 \pm 1.3$ & $3.3 \pm 1.2 y$ & / \\
\hline 22 & PPN-DBS & Moro, 2009 & 6 & $65.2 \pm 2$ & $5 / 1$ & $15.5 \pm 6.2$ & $12 \mathrm{~m}$ & The National Parkinson Alliance \\
\hline 23 & STN-DBS and PPN-DBS & Moreau, 2009 & 4 & l & / & l & / & / \\
\hline 24 & STN-DBS & Kelly, 2009 & 8 & $51.9 \pm 8.7$ & $6 / 2$ & $10.1 \pm 3.5$ & / & $\begin{array}{l}\text { The National Institutes of Health grant } \\
\text { HD-007424 and a grant from Medtronic }\end{array}$ \\
\hline 25 & STN-DBS or GPi-DBS & Katz, 2015 & 235 (S:108 G:127) & 60.9 & $199 / 36$ & 11.8 & $2 y$ & $\begin{array}{l}\text { The Cooperative Studies Program of the } \\
\text { Department of Veterans Affairs Office of } \\
\text { Research and Development, the National } \\
\text { Institute of Neurological } \\
\text { Disorders and Stroke, and Medtronic }\end{array}$ \\
\hline 26 & STN-DBS & Hausdorff, 2009 & 13 & $63.6 \pm 8.7$ & $10 / 3$ & $12.9 \pm 5.6$ & $12 \pm 7 \mathrm{~m}$ & $\begin{array}{l}\text { NIH (AG-14100), the Israel Ministry of } \\
\text { Absorption,the European Union Sixth } \\
\text { Framework Program (FET018474-2, } \\
\text { Dynamic Analysis of Physiological } \\
\text { Networks,DAPHNet, STREP } 045622 \\
\text { SENSing, ect) }\end{array}$ \\
\hline 27 & STN-DBS & $\begin{array}{l}\text { Gervais-bernard, } \\
2009\end{array}$ & 23 & $55.1 \pm 7.2$ & $17 / 6$ & $12.9 \pm 3.2$ & $5 y$ & / \\
\hline 28 & STN-DBS and PPNa-DBS & Ferraye, 2009 & 6 & $63.3 \pm 6.8$ & $4 / 2$ & $20.7 \pm 7.1$ & $1 y$ & $\begin{array}{l}\text { The Michael J. Fox Foundation, the } \\
\text { Fondation de France, the Centre } \\
\text { Hospitalier Universitaire de Grenoble, } \\
\text { project FREESTIPP and Medtronic }\end{array}$ \\
\hline
\end{tabular}




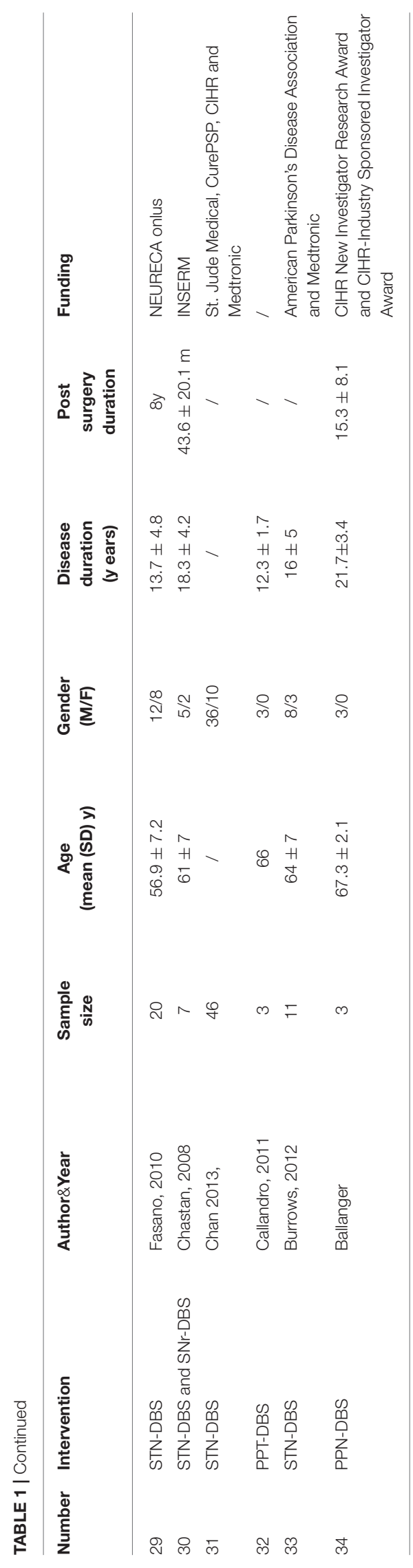

Rodriguez-Oroz et al., 2005; Crenna et al., 2006; Piboolnurak et al., 2007; Tabbal et al., 2007; Temel et al., 2007; Tir et al., 2007; Chastan et al., 2008; Lefaucheur et al., 2008; Ballanger et al., 2009; Ferraye et al., 2009; Gervais-Bernard et al., 2009; Moro et al., 2009; Schneider et al., 2009; Fasano et al., 2010; Kelly et al., 2010; Caliandro et al., 2011; Price et al., 2011; Sidiropoulos et al., 2013; Katz et al., 2015; Vallabhajosula et al., 2015; Welter et al., 2015).

\subsection{Unified Parkinson's Disease Rating Scale III-Gait (Medication-Off/Stimulation-Off vs. Medication-Off/Stimulation-On}

The NMA results of the effect of the stimulation "on and off" on the mean change of the gait of the patients in medicationoff are summarized in Figure 5. In addition, Figure 6 shows the surface under the cumulative ranking (SUCRA). The comparison results of the NMA show that GPi-DBS, STN-DBS, and PPNDBS are superior to the baseline [GPi-DBS: $-0.79(-1.2$, $0.41)$, STN-DBS: $-0.97(-1.1,-0.81)$, and PPN-DBS: $-0.56(-$ $1.1,-0.021)]$. According to the results of the SUCRA scores, STN-DBS (SUCRA $=74.15 \%$ ) ranks first, followed by GPiDBS $($ SUCRA $=48.30 \%)$, and PPN-DBS $($ SUCRA $=27.20 \%)$ ranks last.

\subsection{Unified Parkinson's Disease Rating Scale III-Gait (Medication-On/Stimulation-Off vs. Medication-On/Stimulation-On)}

The NMA results of the effect of the stimulation "on and off" on the mean change of the gait of the patients in medicationon are shown in Figure 5 and the SUCRA is shown in Figure 6. Compared with the baseline, the GPi-DBS and STNDBS proved to be significantly effective [GPi-DBS: $-0.53(-1.0$, $-0.088)$ and STN-DBS: $-0.47(-0.66,-0.29)]$. The SUCRA scores reveal the rank of the three surgical interventions as follows: The GPi-DBS (SUCRA = 59.00\%) ranks first, followed by STNDBS $($ SUCRA $=51.70 \%)$, and PPN-DBS (SUCRA $=35.93 \%)$ ranks last.

\subsection{Unified Parkinson's Disease Rating Scale III-Gait (Medication-Off/Stimulation-Off vs. Medication-On/Stimulation-Off)}

The NMA results show the effect of medication "on and off” on the mean change of the gait of the patients in stimulationoff (Figure 5), the SUCRA is shown in Figure 6. The GPi-DBS, STN-DBS, and PPN-DBS show effective improvement compared to the baseline [GPi-DBS: $-1.4(-2.1,-0.82)$, STN-DBS: $-1.2(-$ $1.5,-0.90)$, and PPN-DBS: $-1.1(-1.9,-0.34)]$. The rank of the three surgical interventions is that based on the SUCRA scores that is as follows: The GPi-DBS (SUCRA = 67.75\%) ranks first, followed by STN-DBS (SUCRA $=44.80 \%$ ), and PPN-DBS $($ SUCRA $=37.40 \%)$ ranks last. 


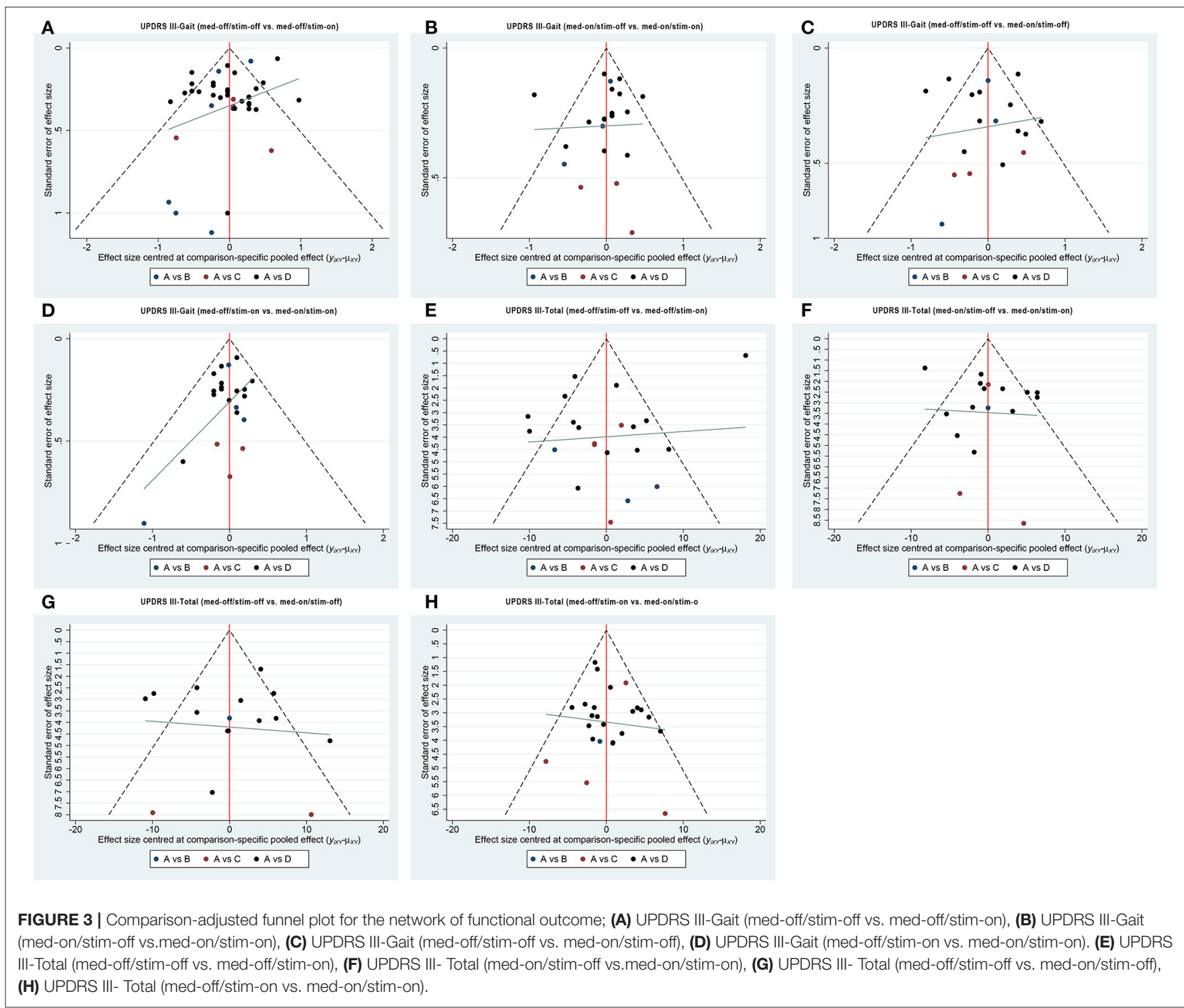

\subsection{Unified Parkinson's Disease Rating Scale III-Gait (Medication-Off/Stimulation-On vs. Medication-On/Stimulation-On)}

The NMA results of the effect of the medication "on and off" on the mean change of the gait of the patients in stimulation-on are shown in Figure 5 and the SUCRA is shown in Figure 6. The comparison results of the NMA show that the GPi-DBS, STN-DBS, and PPN-DBS are superior to the baseline [GPi-DBS: $-0.89(-1.1,-0.63)$, STN-DBS: $-0.40(-0.52,-0.29)$, and PPN-DBS: $-0.83(-1.5$, $-0.20)$ ]. According to the results of the SUCRA, the GPiDBS (SUCRA $=68.36 \%$ ) ranks first, followed by PPN-DBS $($ SUCRA $=61.50 \%)$, and the STN-DBS $($ SUCRA $=20.03 \%)$ ranks last.

\subsection{Unified Parkinson's Disease Rating Scale III-Total (Medication-Off/Stimulation-Off vs. Medication-Off/Stimulation-On)}

The secondary results of discontinuation are motor symptoms. The NMA results show the effect of stimulation "on and off" on the mean change of the gait of the patients in medication-off (Figure 7), and the SUCRA is shown in Figure 8. Compared with baseline, the GPi-DBS and STN-DBS proved to be significantly effective [GPi-DBS: $-16.0(-26.0,-4.7)$ and STN-DBS: $-22.0(-26.0,-17.0)]$. The SUCRA scores reveal that the rank of the three surgical interventions is as follows: The STN-DBS (SUCRA $=78.70 \%$ ) ranks first, followed by GPiDBS $($ SUCRA $=52.77 \%)$, and PPN-DBS (SUCRA $=15.77 \%)$ ranks last. 


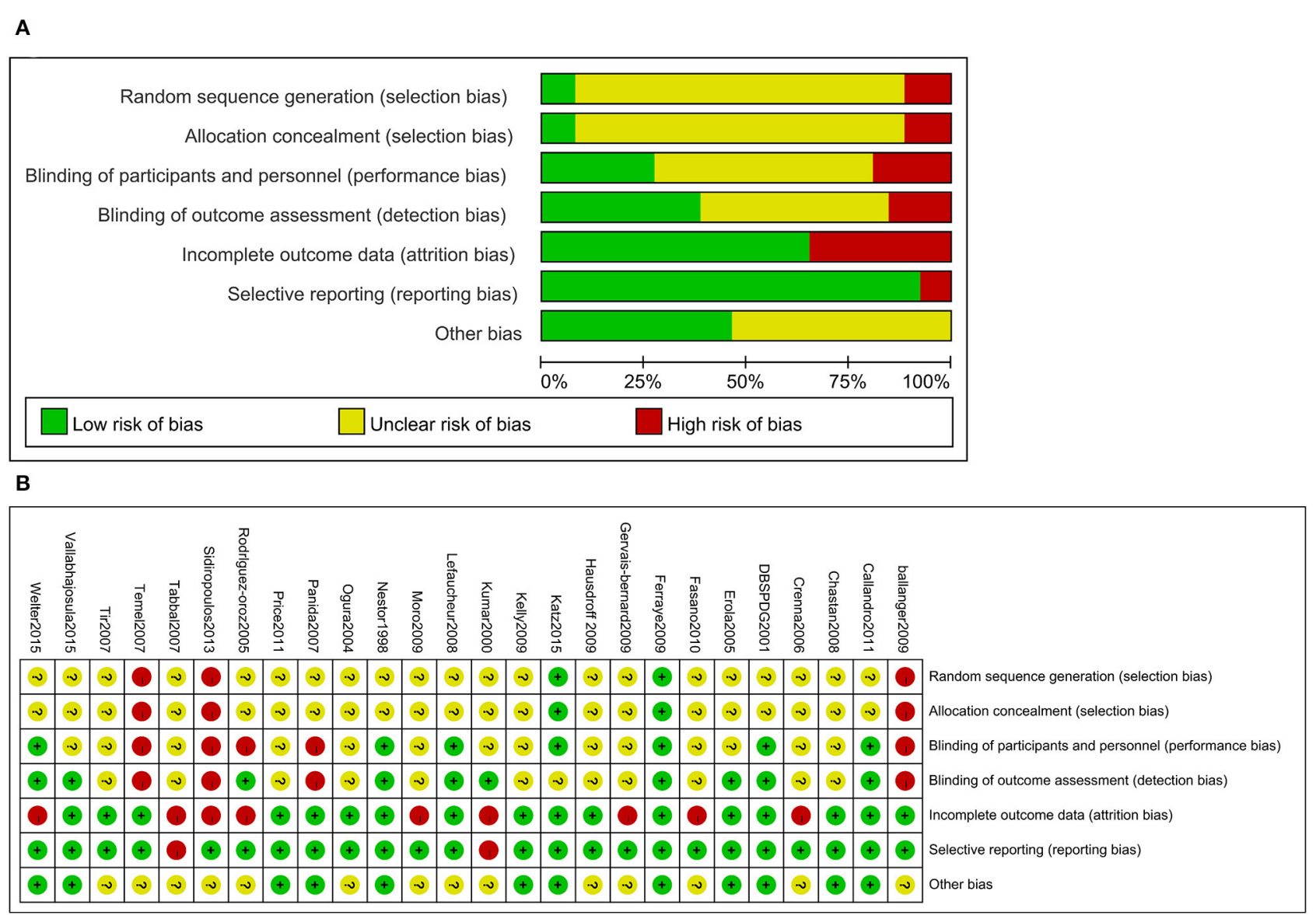

FIGURE 4 | Risk of bias for the included trials (A). Risk of bias summary for the included trials (B)

\subsection{Unified Parkinson's Disease Rating Scale III-Total \\ (Medication-On/Stimulation-Off vs. Medication-On/Stimulation-On)}

The NMA results of the effect of the stimulation "on and off" on the mean change of the gait of the patients in medication-on are summarized in Figure 7. In addition, the SUCRA is shown in Figure 8. The STN-DBS has effective improvement compared to the baseline [STN-DBS: $-6.4(-9.3,-3.5)]$. The SUCRA scores reveal that the rank of the three surgical interventions is as follows: the STN-DBS (SUCRA = 62.43\%) ranks first, followed by GPi-DBS (SUCRA $=47.20 \%$ ), and the PPN-DBS (SUCRA $=33.87 \%)$ ranks last.

\subsection{Unified Parkinson's Disease Rating Scale III-Total (Medication-Off/Stimulation-Off vs. Medication-On/Stimulation-Off)}

The NMA results of the effect of the medication "on and off" on the mean change of the gait of the patients in stimulationoff are summarized in Figure 7. In addition, SUCRA is shown in Figure 8. Compared with the baseline, the GPi-DBS and STNDBS proved to be significantly effective [GPi-DBS: $-33.0(-49.0$,
$-17.0)$ and STN-DBS: $-24.0(-29.0,-19.0)]$. According to the SUCRA scores, the GPi-DBS (SUCRA $=78.61 \%$ ) ranks first, followed by STN-DBS (SUCRA $=54.07 \%$ ), and the PPN-DBS $($ SUCRA $=16.57 \%)$ ranks last.

\subsection{Unified Parkinson's Disease Rating Scale III-Total (Medication-Off/Stimulation-On vs. Medication-On/Stimulation-On)}

The NMA results of the effect of the medication "on and off" on the mean change of the gait of the patients in stimulation-on are shown in Figure 7 and the SUCRA is shown in Figure 8. The GPi-DBS, STN-DBS, and PPN-DBS show effective improvement compare to the baseline [GPi-DBS: 15.0(-21.0, -8.7), STN-DBS: -7.1(-8.5, -5.5), and PPN-DBS: $9.0(-13.0,-5.2)]$. According to the SUCRA scores, the GPiDBS (SUCRA $=80.86 \%$ ) ranks first, followed by PPN-DBS $($ SUCRA $=48.40 \%)$, and the STN-DBS $($ SUCRA $=22.73 \%)$ ranks last.

\subsection{Consistency and Integration Analysis, Small-Scale Research Effects}

In this study, we assessed the inconsistency between the included studies by constructing a consistency model and an inconsistency 


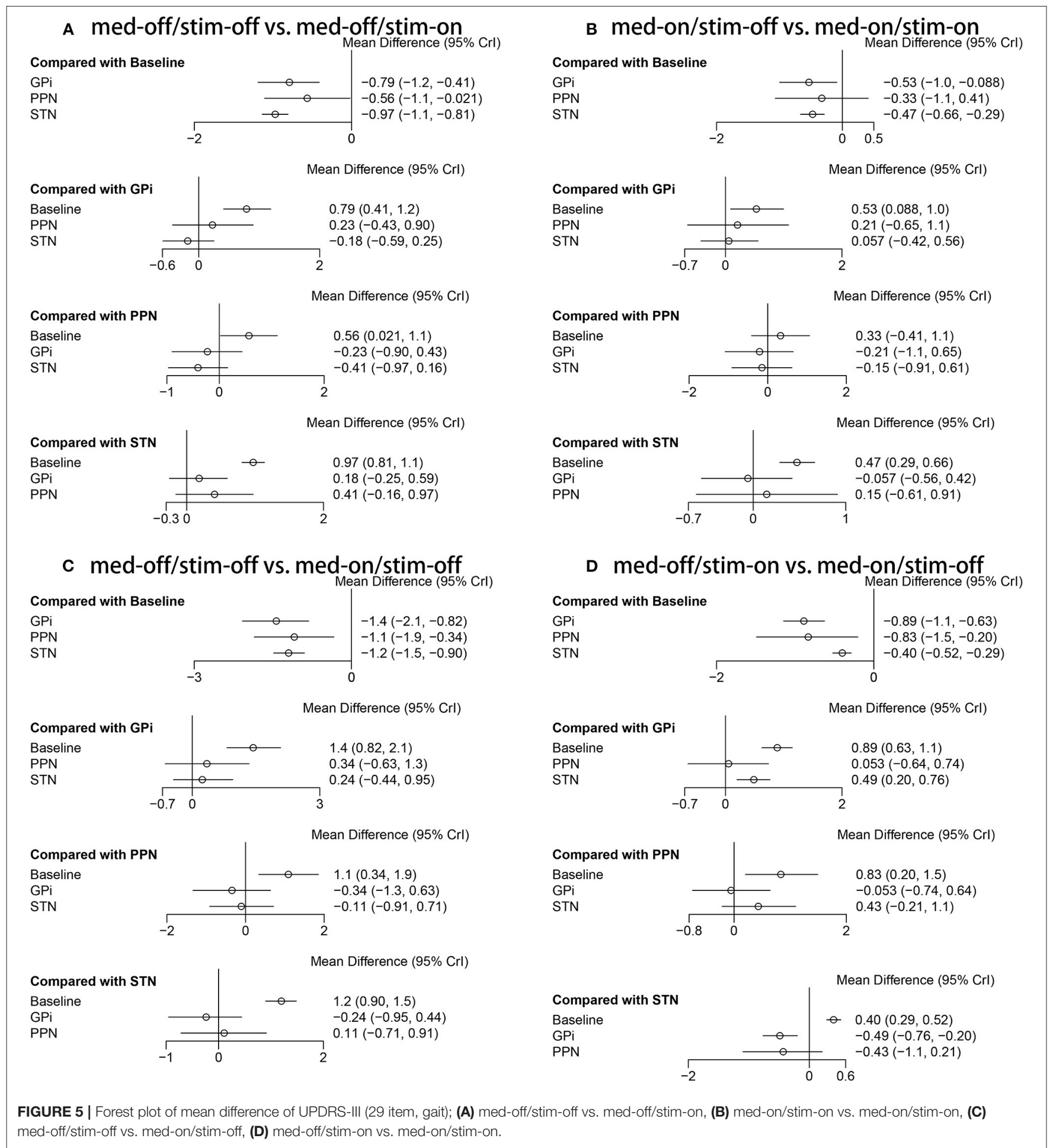

model. The results show that the difference in DIC between these two models was less than 1 . Thus, the consistency model is reliable. In addition, by limiting the value of all potential proportional reduction factors of different parameters to 1 , it is demonstrated that the algorithm has good convergence efficiency. Moreover, we did not find a small-scale research effect.

\section{DISCUSSION}

This study includes data from 34 clinical trials (538 patients) and systematically reviews the treatment of PD gait with different DBS targets and NMA. This study found that STN-DBS is the best treatment option to improve PD gait, while GPi-DBS is the best to improve PD gait under medication. STN-DBS ranked 


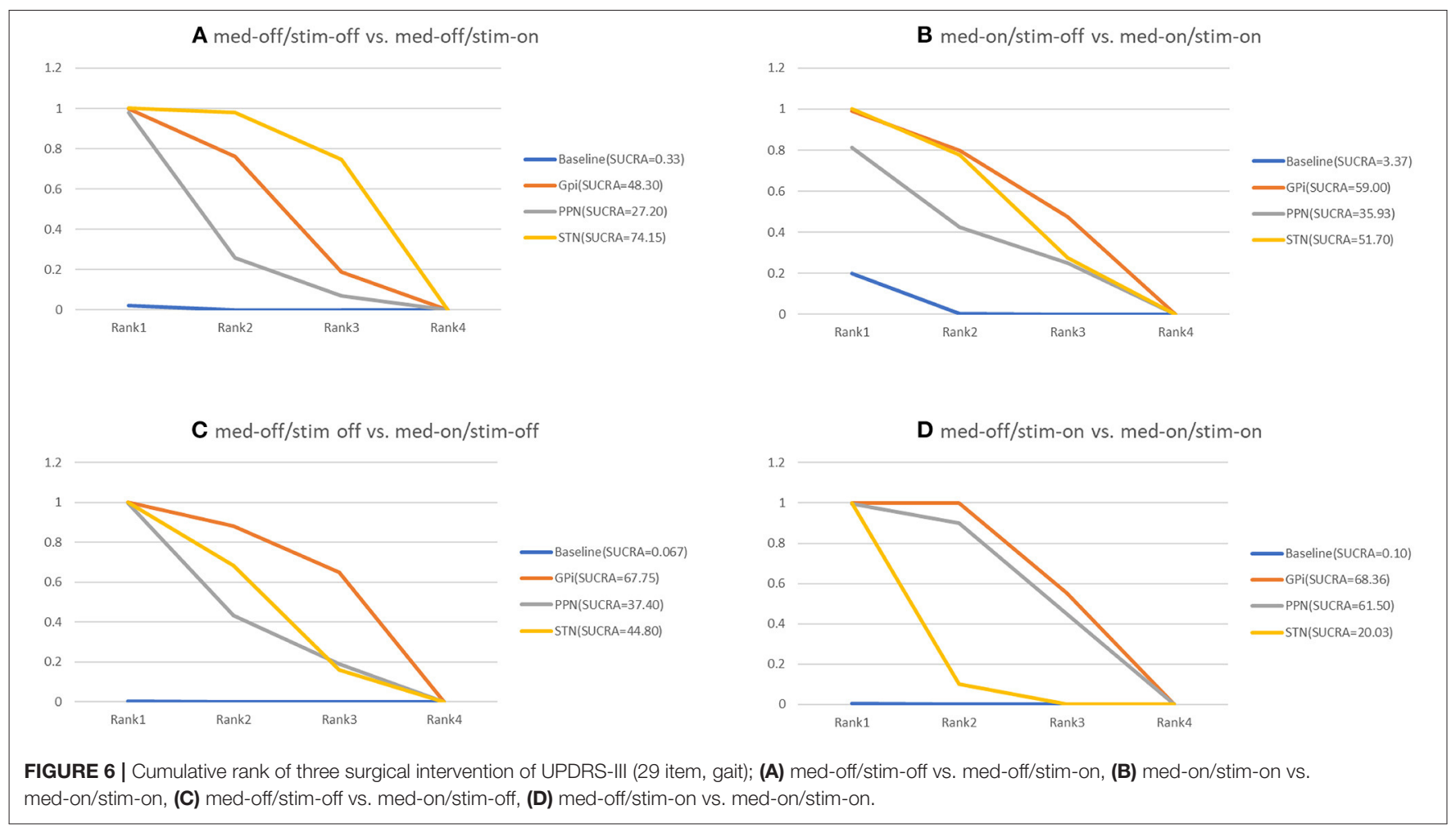

first in improving PD gait and motor symptoms and can greatly increase the stride length and increase the gait speed in the drug withdrawal state, while the rhythm remains mostly unchanged (Allert et al., 2001; Faist, 2001; Liu et al., 2005). At the same time, it also increases the swing motion amplitude of the arms and legs (Carpinella et al., 2007). STN- DBS also counteracts the asymmetry of foot position in pathological space, resulting in a more physiologically alternating gait cycle (Johnsen et al., 2009). Our findings are consistent with the findings of most previous studies. STN-DBS ranked first in improving the UPDRS III-29 gait score in the drug withdrawal state.

In principle, the effect of STN-DBS on gait parameters is similar to that of over-dose levodopa (L-dopa) (Cantiniaux et al., 2009; Hausdorff et al., 2009; Gulberti et al., 2015; Muthuraman et al., 2018), although L-DOPA sometimes has a slight impact on increasing step length and gait speed (Stolze et al., 2001; Lubik et al., 2006). Compared with any other treatment, the comprehensive effect of L-DOPA combined with STN-DBS is better than the effect of each alone (Hausdorff et al., 2009). In this study, the results of comparing the effects of L-dopa and STNDBS are consistent with the general observation that STN-DBS can improve the symptoms of patients with dopamine-responsive PD (Pötter-Nerger and Volkmann, 2013). Our study found that GPi-DBS is more effective than STN-DBS in improving PD gait under medication. The effect of GPi-DBS on gait is different from that of STN-DBS. The GPi-DBS primarily affects gait speed, while STN-DBS primarily affects step length without changing the rhythm (Allert et al., 2001). Some studies have shown that GPi-DBS significantly improves the axial symptoms of untreated patients with PD in the first year after surgery, and this effect is not obvious under the state of drug treatment (Bakker et al., 2004). For gait and balance problems in patients with PD, the choice of GPi or STN as the target remains a matter of controversy.

A meta-analysis showed that when combined with drugs, the effect of STN-high-frequency stimulation (STN-HFS) on postural instability and gait disorder (PIGD) symptoms gradually worsened and reached the preoperative level within 2 years, while the effect of GPi-HFS combined with drugs remained stable over time (George et al., 2010). This may be due to the superiority of GPi-DBS over STN-DBS in the long-term efficacy of PIGD. However, the judgment on the relative benefit of GPi vs. STN surgery for PIGD must consider that GPi-HFS patients receive more levodopa than STN-HFS patients under combination therapy. Besides, there are few long-term studies evaluating GPi-HFS, and further randomized controlled trials and long-term follow-up trials are needed (George et al., 2010; Pötter-Nerger and Volkmann, 2013).

The PPN was introduced as a possible stimulation target for the treatment of gait disorders in patients with advanced PD (Broen et al., 2011). The PPN located in the midbrain and the upper bridge cover is classically identified by its main cholinergic neurons. Due to its extensive connections with other areas of the brain and spinal cord, the PPN is considered to be an important part of the "mesencephalic locomotor region" (MLR), which has been shown to be an upper spinal cord that can initiate and regulate movement (Ryczko and Dubuc, 2013). Plaha study (Plaha and Gill, 2005) shows that PPN-DBS has a possible therapeutic effect on gait disorders in patients with advanced PD. The previous published meta-analysis on 


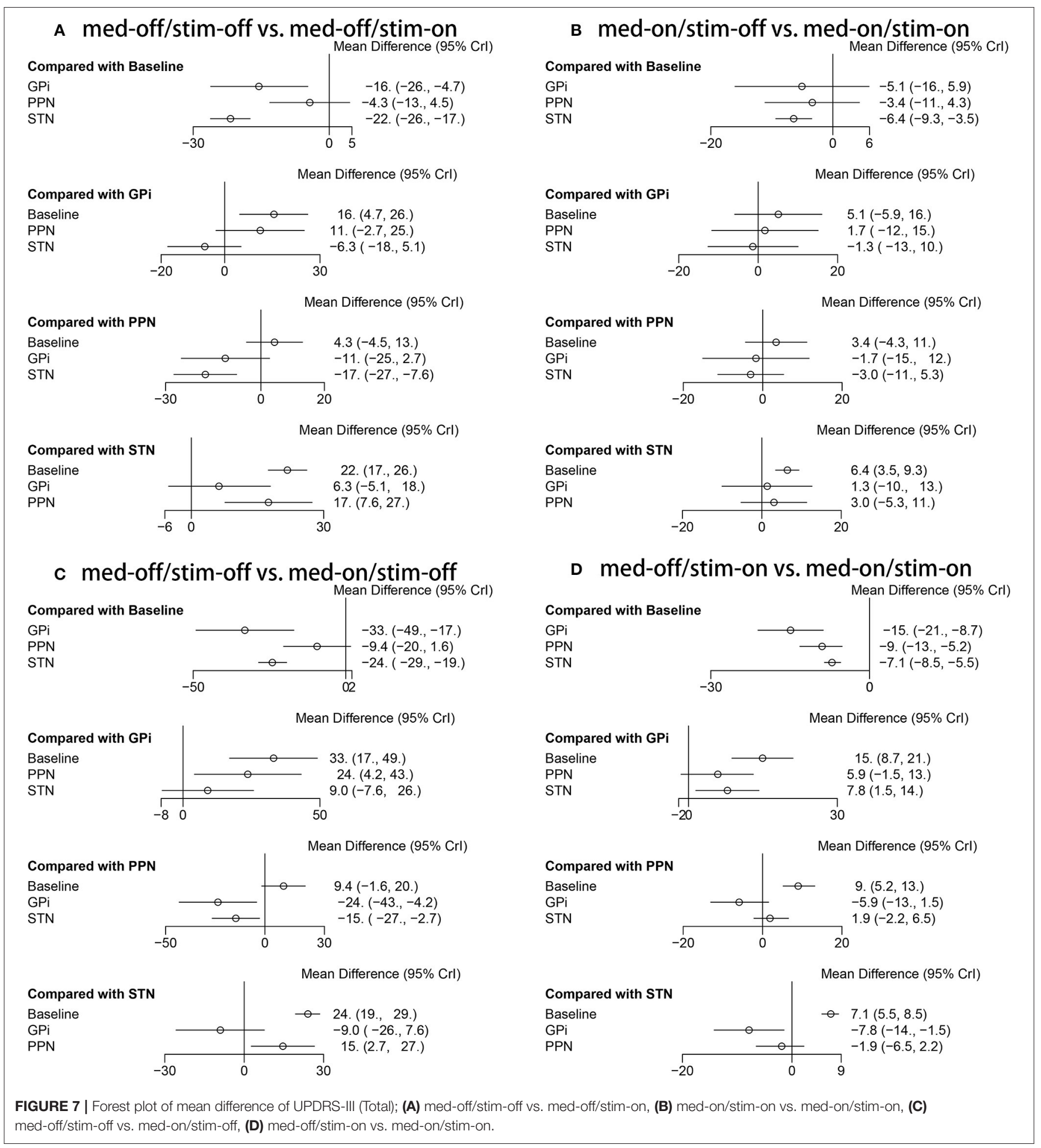

the efficacy of PPN-DBS on PD gait indicates that PPN-DBS can greatly improve PD-related gait disorders (Lin et al., 2020). The results of this NMA show that PPN-DBS is effective in improving the gait score of UPDRS III-29 during the drug off period compared to baseline, but it ranks behind STN-DBS and GPi-DBS. In addition, PPN-DBS also ranks last in the improvement of the motor symptom score of patients with PD, which was not significant compared with the baseline. PPN-DBS is a promising therapy for axial motor deficits in PD, particularly gait freezing and falls (Thevathasan et al., 2017; Lin et al., 2020). The enrolled studies included patients with PD, which mainly included patients with stiffness, tremor, and postural gait 


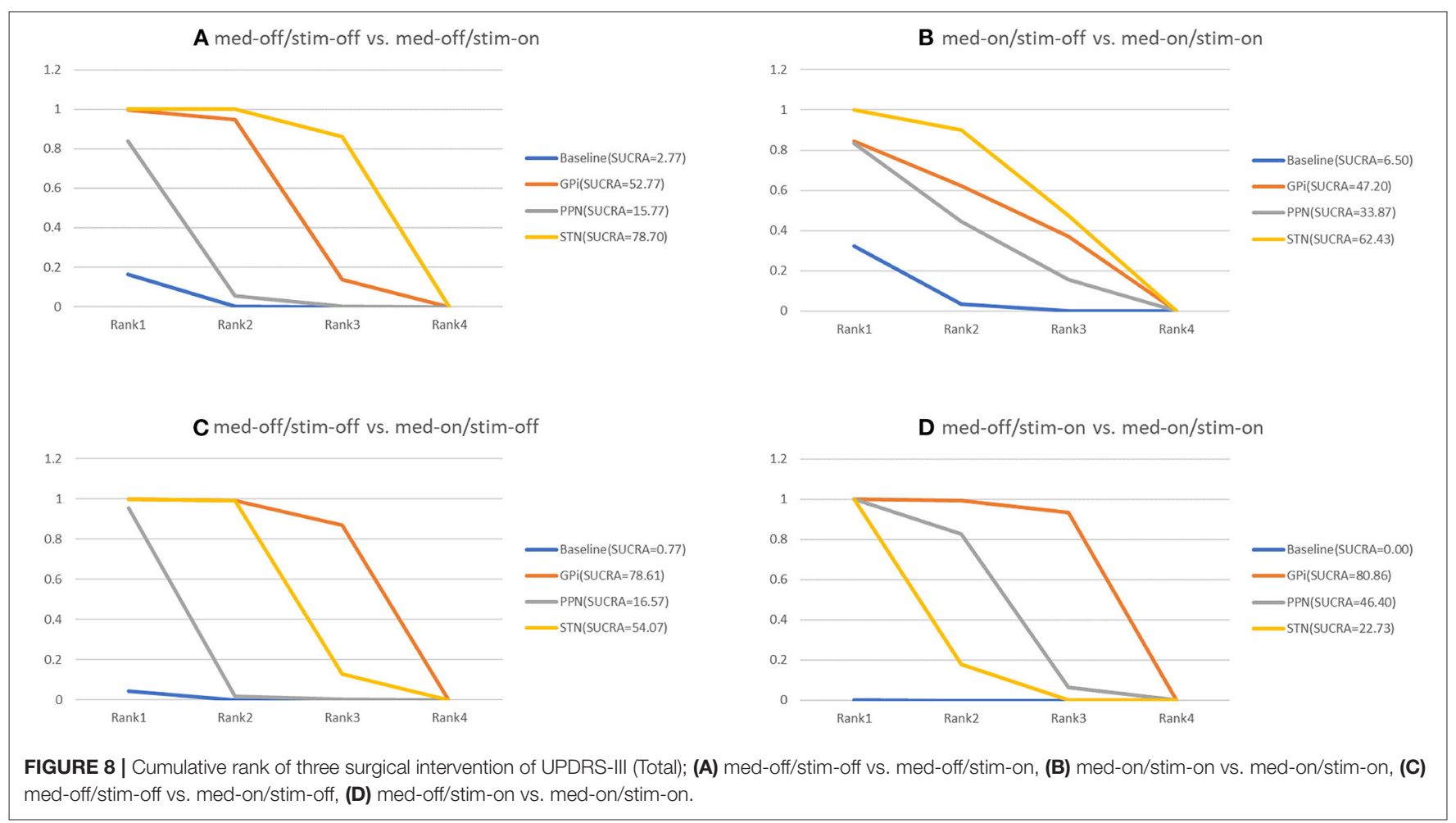

disorder. Hence, the results of the study show the effectiveness in PPN-DBS lower than STN-DBS and GPi-DBS. The original data of the included article did not provide specific types of patients, and we could not further subgroup analysis to evaluate axial motor deficits in PD.

This study has certain limitations. First, in this study, age and sex were not taken into account, and the patient population that underwent different DBS targets were imbalanced. Second, the UPDRS III-gait is not very sensitive in detecting the gait improvement in patients with PD. Third, the evaluation of long-term efficacy requires further research studies. Fourth, the parameters of DBS were not considered, which caused a certain deviation. Finally, our conclusion involves indirect comparison and since NMA combines direct and indirect comparisons that include observational evidence, the inherent differences between trials was not considered and bias were added when assessing effects.

\section{CONCLUSION}

Although both STN-DBS and GPi-DBS can affect some aspects of PD gait disorder, the treatment of gait disorder in $\mathrm{PD}$ is still a

\section{REFERENCES}

Allert, N., Volkmann, J., Dotse, S., Hefter, H., Sturm, V., and Freund, H.-J. (2001). Effects of bilateral pallidal or subthalamic stimulation on gait in advanced parkinson's disease. Mov. Disord. 16, 1076-1085. doi: 10.1002/mds.1222 challenge. Our study compared and ranked three stimulus targets for the treatment of $\mathrm{PD}$, and the results can help clinicians choose reasonable treatment strategies for patients with $\mathrm{PD}$.

\section{DATA AVAILABILITY STATEMENT}

The original contributions presented in the study are included in the article/Supplementary Material, further inquiries can be directed to the corresponding author.

\section{AUTHOR CONTRIBUTIONS}

TC contributed to the data processing. FL contributed to the data Extraction. GC contributed to the overall design. All authors contributed to the article and approved the submitted version.

\section{SUPPLEMENTARY MATERIAL}

The Supplementary Material for this article can be found online at: https://www.frontiersin.org/articles/10.3389/fnhum. 2021.749722/full\#supplementary-material 
stereotactic neurosurgery on postural instability and gait in parkinson's disease. Mov. Disord. 19, 1092-1099. doi: 10.1002/mds. 20116

Ballanger, B., Lozano, A. M., Moro, E., van Eimeren, T., Hamani, C., Chen, R., et al. (2009). Cerebral blood flow changes induced by pedunculopontine nucleus stimulation in patients with advanced parkinson's disease: a [15o] h2o PET study. Hum. Brain Mapp. 30, 3901-3909. doi: 10.1002/hbm. 20815

Broen, M., Duits, A., Visser-Vandewalle, V., Temel, Y., and Winogrodzka, A. (2011). Impulse control and related disorders in parkinson's disease patients treated with bilateral subthalamic nucleus stimulation: a review. Parkinsonism Relat. Disord. 17, 413-420. doi: 10.1016/j.parkreldis.2011.02.013

Caliandro, P., Insola, A., Scarnati, E., Padua, L., Russo, G., Granieri, E., et al. (2011). Effects of unilateral pedunculopontine stimulation on electromyographic activation patterns during gait in individual patients with parkinson's disease. J. Neural Transm. 118, 1477-1486. doi: 10.1007/s00702-011-0705-7

Cantiniaux, S., Vaugoyeau, M., Robert, D., Horrelou-Pitek, C., Mancini, J., Witjas, T., et al. (2009). Comparative analysis of gait and speech in parkinson's disease: hypokinetic or dysrhythmic disorders? J. Neurol. Neurosurg. Psychiatry 81, 177-184. doi: 10.1136/jnnp.2009.174375

Carpinella, I., Crenna, P., Marzegan, A., Rabuffetti, M., Rizzone, M., Lopiano, L., et al. (2007). Effect of l-dopa and subthalamic nucleus stimulation on arm and leg swing during gait in parkinson's disease. Annu. Int. Conf. IEEE Eng. Med. Biol. Soc. 2007, 6665-6668. doi: 10.1109/IEMBS.2007.4353888

Chastan, N., Westby, G. W. M., Yelnik, J., Bardinet, E., Do, M. C., Agid, Y., et al. (2008). Effects of nigral stimulation on locomotion and postural stability in patients with parkinson's disease. Brain 132, 172-184. doi: 10.1093/brain/awn294

Crenna, P., Carpinella, I., Rabuffetti, M., Rizzone, M., Lopiano, L., Lanotte, M., et al. (2006). Impact of subthalamic nucleus stimulation on the initiation of gait in parkinson's disease. Exp. Brain Res. 172, 519-532. doi: 10.1007/s00221-006-0360-7

Dias, S., and Caldwell, D. (2019). Network meta-analysis explained. Arch. Dis. Child. Fetal Neonatal Ed. 104, 8-12. doi: 10.1136/archdischild-2018-315224

Erola, T., Heikkinen, E. R., Haapaniemi, T., Tuominen, J., Juolasmaa, A., and Myllylä, V. V. (2005). Efficacy of bilateral subthalamic nucleus (STN) stimulation in parkinson's disease. Acta Neurochir. 148, 389-394. doi: 10.1007/s00701-005-0662-8

Faist, M. (2001). Effect of bilateral subthalamic nucleus stimulation on gait in parkinson's disease. Brain 124, 1590-1600. doi: 10.1093/brain/124.8.1590

Fasano, A., Romito, L., Piano, D., Zinno, C., Bentivoglio, M., Albanese, A., et al. (2010). Motor and cognitive outcome in patients with parkinson's disease 8 years after subthalamic implants. Brain 133, 2664-2676. doi: 10.1093/brain/awq221

Ferraye, M. U., Debu, B., Fraix, V., Goetz, L., Ardouin, C., Yelnik, J., et al. (2009). Effects of pedunculopontine nucleus area stimulation on gait disorders in parkinson's disease. Brain 133, 205-214. doi: 10.1093/brain/awp229

Ferraye, M. U., Debû, B., and Pollak, P. (2008). Deep brain stimulation effect on freezing of gait. Mov. Disord. 23, S489-S494. doi: 10.1002/mds.21975

Gálvez-Jiménez, N., Lozano, A., Tasker, R., Duff, J., Hutchison, W., and Lang, A. E. (1998). Pallidal stimulation in parkinson's disease patients with a prior unilateral pallidotomy. Can. J. Neurol. Sci. 25, 300-305. doi: 10.1017/S0317167100034314

Gazewood, J., Richards, D., and Clebak, K. (2013). Parkinson disease: an update. Am. Fam Physician 87, 267-273. doi: 10.1097/01.nrl.0000131146.08278.a5

George, R. J. S., Nutt, J. G., Burchiel, K. J., and Horak, F. B. (2010). A metaregression of the long-term effects of deep brain stimulation on balance and gait in pd. Neurology 75, 1292-1299. doi: 10.1212/WNL.0b013e3181 f61329

Gervais-Bernard, H., Xie-Brustolin, J., Mertens, P., Polo, G., Klinger, H., Adamec, D., et al. (2009). Bilateral subthalamic nucleus stimulation in advanced parkinson's disease: five year follow-up. J. Neurol. 256, 225-233. doi: 10.1007/s00415-009-0076-2

Gulberti, A., Moll, C., Hamel, W., Buhmann, C., Koeppen, J., Boelmans, K., et al. (2015). Predictive timing functions of cortical beta oscillations are impaired in parkinson's disease and influenced by l-dopa and deep brain stimulation of the subthalamic nucleus. Neuroimage Clin. 9, 436-449. doi: 10.1016/j.nicl.2015.09.013
Hausdorff, J. M., Gruendlinger, L., Scollins, L., O’Herron, S., and Tarsy, D. (2009). Deep brain stimulation effects on gait variability in parkinson's disease. Mov. Disord. 24, 1688-1692. doi: 10.1002/mds.22554

Jahanshahi, M., Obeso, I., Baunez, C., Alegre, M., and Krack, P. (2015). Parkinson's disease, the subthalamic nucleus, inhibition, and impulsivity. Mov. Disord. 30, 128-168. doi: 10.1002/mds.26049

Johnsen, E., Mogensen, P., Sunde, N., and Østergaard, K. (2009). Improved asymmetry of gait in parkinson's disease with dbs: gait and postural instability in parkinson's disease treated with bilateral deep brain stimulation in the subthalamic nucleus. Mov. Disord. 24, 590-597. doi: 10.1002/mds.22419

Katz, M., Luciano, M., Carlson, K., Luo, P., Marks, W., Larson, P., et al. (2015). Csp 468 study group. differential effects of deep brain stimulation target on motor subtypes in parkinson's disease. Ann. Neurol. 77, 710-719. doi: 10.1002/ana.24374

Kelly, V., Israel, S., Samii, A., Slimp, J., Goodkin, R., and Shumway-Cook, A. (2010). Assessing the effects of subthalamic nucleus stimulation on gait and mobility in people with parkinson disease. Disabil. Rehabil. 32, 929-965. doi: 10.3109/09638280903374139

Kumar, K., Kelly, M., and Toth, C. (1999). Deep brain stimulation of the ventral intermediate nucleus of the thalamus for control of tremors in parkinson's disease and essential tremor. Stereotact. Funct. Neurosurg. 72, 47-61. doi: 10.1159/000029671

Lefaucheur, J., Gurruchaga, J., Pollin, B., Von Raison, F., Mohsen, N., Shin, M., et al. (2008). Outcome of bilateral subthalamic nucleus stimulation in the treatment of parkinson's disease: correlation with intra-operative multi-unit recordings but not with the type of anaesthesia. Eur. Neurol. 60, 186-199. doi: $10.1159 / 000148246$

Lin, F., Wu, D., Lin, C., Cai, H., Chen, L., Cai, G., et al. (2020). Pedunculopontine nucleus deep brain stimulation improves gait disorder in parkinson's disease: a systematic review and meta-analysis. Neurochem. Res. 45, 709-719. doi: 10.1007/s11064-020-02962-y

Lin, F., Wu, D., Yu, J., Weng, H., Chen, L., Meng, F., et al. (2021). Comparison of efficacy of deep brain stimulation and focused ultrasound in parkinsonian tremor: a systematic review and network meta-analysis. J. Neurol. Neurosurg. Psychiatry 92, 434-443. doi: 10.1136/jnnp-2020-323656

Liu, W., McIntire, K., Kim, S. H., Zhang, J., Dascalos, S., Lyons, K. E., et al. (2005). Quantitative assessments of the effect of bilateral subthalamic stimulation on multiple aspects of sensorimotor function for patients with parkinson's disease. Parkinsonism Relat. Disord. 11, 503-508. doi: 10.1016/j.parkreldis.2005.07.001

Lubik, S., Fogel, W., Tronnier, V., Krause, M., König, J., and Jost, W. (2006). Gait analysis in patients with advanced parkinson disease: different or additive effects on gait induced by levodopa and chronic stn stimulation. J. Neural Transm. 113, 163-173. doi: 10.1007/s00702-005-0310-8

Moro, E., Hamani, C., Poon, Y.-Y., Al-Khairallah, T., Dostrovsky, J. O., Hutchison, W. D., et al. (2009). Unilateral pedunculopontine stimulation improves falls in parkinson's disease. Brain. Brain 133, 215-224. doi: 10.1093/brain/awp261

Movement Disorder Society Task Force on Rating Scales for Parkinson's Disease (2003). Movement disorder society task force on rating scales for parkinson's disease. the unified parkinson's disease rating scale (updrs): status and recommendations. Mov. Disord. 18, 738-750. doi: 10.1002/mds.10473

Muthuraman, M., Koirala, N., Ciolac, D., Pintea, B., Glaser, M., Groppa, S., et al. (2018). Deep brain stimulation and l-dopa therapy: concepts of action and clinical applications in parkinson's disease. Front. Neurol. 9:711. doi: 10.3389/fneur.2018.00711

Nikolakopoulou, A., Mavridis, D., Furukawa, T. A., Cipriani, A., Tricco, A. C., Straus, S. E., et al. (2018). Living network meta-analysis compared with pairwise meta-analysis in comparative effectiveness research: empirical study. BMJ 360:585. doi: 10.1136/bmj.k585

Nonnekes, J., Ružicka, E., Nieuwboer, A., Hallett, M., Fasano, A., and Bloem, B. (2019). Compensation strategies for gait impairments in parkinson disease: a review. JAMA Neurol. 76, 718-743. doi: 10.1001/jamaneurol.2019.0033

Nonnekes, J., Snijders, A., Nutt, J., Deuschl, G., Giladi, N., and Bloem, B. (2015). Freezing of gait: a practical approach to management. Lancet Neurol. 14, 768-778. doi: 10.1016/S1474-4422(15)00041-1

Obeso, J., Olanow, C., Rodriguez-Oroz, M., Krack, P., Kumar, R., and Lang, A. (2001). Deep-brain stimulation of the subthalamic nucleus or the pars interna of the globus pallidus in parkinson's disease. N. Engl. J. Med. 345, 956-963. doi: 10.1056/NEJMoa000827 
Ogura, M., Nakao, N., Nakai, E., Uematsu, Y., and Itakura, T. (2004). The mechanism and effect of chronic electrical stimulation of the globus pallidus for treatment of parkinson disease. J. Neurosurg. 100, 997-1001. doi: 10.3171/jns.2004.100.6.0997

Okun, M. S. (2012). Deep-brain stimulation for parkinson's disease. N. Engl. J. Med. 367, 1529-1538. doi: 10.1056/NEJMct1208070

Piboolnurak, P., Lang, A. E., Lozano, A. M., Miyasaki, J. M., Saint-Cyr, J. A., Poon, Y.-Y. W., et al. (2007). Levodopa response in long-term bilateral subthalamic stimulation for parkinson's disease. Mov. Disord. 22, 990-997. doi: $10.1002 / \mathrm{mds} .21482$

Plaha, P., and Gill, S. S. (2005). Bilateral deep brain stimulation of the pedunculopontine nucleus for parkinson's disease. Neuroreport 16, 1883-1887. doi: 10.1097/01.wnr.0000187637.20771.a0

Pötter-Nerger, M., and Volkmann, J. (2013). Deep brain stimulation for gait and postural symptoms in parkinson's disease. Mov. Disord. 28, 1609-1615. doi: $10.1002 / \mathrm{mds} .25677$

Price, C. C., Favilla, C., Tanner, J. J., Towler, S., Jacobson, C. E., Hass, C. J., et al. (2011). Lateral ventricle volume is poor predictor of post unilateral DBS motor change for parkinson's disease. Parkinsonism Relat. Disord. 17, 343-347. doi: 10.1016/j.parkreldis.2011.01.018

Remple, M. S., Bradenham, C. H., Kao, C. C., Charles, P. D., Neimat, J. S., and Konrad, P. E. (2011). Subthalamic nucleus neuronal firing rate increases with parkinson's disease progression. Mov. Disord. 26, 1657-1662. doi: $10.1002 / \mathrm{mds} .23708$

Rodriguez-Oroz, M. C., Obeso, J. A., Lang, A. E., Houeto, J.-L., Pollak, P., Rehncrona, S., et al. (2005). Bilateral deep brain stimulation in parkinson's disease: a multicentre study with 4 years follow-up. Brain 128, 2240-2249. doi: 10.1093/brain/awh571

Ryczko, D., and Dubuc, R. (2013). The multifunctional mesencephalic locomotor region. Curr. Pharm. Des. 19, 4448-4470. doi: 10.2174/1381612811319240011

Schneider, S., Paisan-Ruiz, C., Garcia-Gorostiaga, I., Quinn, N., Weber, Y., Lerche, H., et al. (2009). Glutl gene mutations cause sporadic paroxysmal exerciseinduced dyskinesias. Mov. Disord. 24, 1684-1692. doi: 10.1002/mds.22507

Sidiropoulos, C., Walsh, R., Meaney, C., Poon, Y. Y., Fallis, M., and Moro, E. (2013). Low-frequency subthalamic nucleus deep brain stimulation for axial symptoms in advanced parkinson's disease. J. Neurol. 260, 2306-2311. doi: 10.1007/s00415-013-6983-2

Stolze, H., Klebe, S., Poepping, M., Lorenz, D., Herzog, J., Hamel, W., et al. (2001). Effects of bilateral subthalamic nucleus stimulation on parkinsonian gait. Neurology 57, 144-146. doi: 10.1212/WNL.57.1.144

Tabbal, S., Revilla, F., Mink, J., Schneider-Gibson, P., Wernle, A., De Erausquin, G., et al. (2007). Safety and efficacy of subthalamic nucleus deep brain stimulation performed with limited intraoperative mapping for treatment of parkinson's disease. Neurosurgery 61, 119-146. doi: 10.1227/01.neu.0000289725. 97211.51

Temel, Y., Wilbrink, P., Duits, A., Boon, P., Tromp, S., Ackermans, L., et al. (2007). Single electrode and multiple electrode guided electrical stimulation of the subthalamic nucleus in advanced parkinson's disease. Neurosurgery 61, 355-362. doi: 10.1227/01.neu.0000303993.82149.98

Thevathasan, W., Debu, B., Aziz, T., Bloem, B. R., Blahak, C., Butson, C., et al. (2017). Pedunculopontine nucleus deep brain stimulation in parkinson's disease: a clinical review. Mov. Disord. 33, 10-20. doi: 10.1002/mds. 27098

Tir, M., Devos, D., Blond, S., Touzet, G., Reyns, N., Duhamel, A., et al. (2007) Exhaustive, one-year follow-up of subthalamic nucleus deep brain stimulation in a large, single-center cohort of parkinsonian patients. Neurosurgery 61, 297-304. doi: 10.1227/01.NEU.0000285347.50028.B9

Vallabhajosula, S., Haq, I. U., Hwynn, N., Oyama, G., Okun, M., Tillman, M. D., et al. (2015). Low-frequency versus high-frequency subthalamic nucleus deep brain stimulation on postural control and gait in parkinson's disease: a quantitative study. Brain Stimul. 8, 64-75. doi: 10.1016/j.brs.2014. 10.011

Welter, M.-L., Demain, A., Ewenczyk, C., Czernecki, V., Lau, B., Helou, A. E., et al. (2015). PPNa-DBS for gait and balance disorders in parkinson's disease: a double-blind, randomised study. J. Neurol. 262, 1515-1525. doi: $10.1007 /$ s00415-015-7744-1

Conflict of Interest: The authors declare that the research was conducted in the absence of any commercial or financial relationships that could be construed as a potential conflict of interest.

Publisher's Note: All claims expressed in this article are solely those of the authors and do not necessarily represent those of their affiliated organizations, or those of the publisher, the editors and the reviewers. Any product that may be evaluated in this article, or claim that may be made by its manufacturer, is not guaranteed or endorsed by the publisher.

Copyright (c) 2021 Chen, Lin and Cai. This is an open-access article distributed under the terms of the Creative Commons Attribution License (CC BY). The use, distribution or reproduction in other forums is permitted, provided the original author(s) and the copyright owner(s) are credited and that the original publication in this journal is cited, in accordance with accepted academic practice. No use, distribution or reproduction is permitted which does not comply with these terms. 